\title{
ENGINEERING STABLE TOPOGRAPHY IN DENSE BIO-MIMETIC 3D COLLAGEN SCAFFOLDS
}

\author{
T Alekseeva ${ }^{1^{*}}$, E Hadjipanayi $1^{1^{*}}$, EA Abou Neel $^{2}$ and RA Brown ${ }^{1 *}$ \\ ${ }^{1}$ University College London, Tissue Repair and Engineering Centre, Institute of Orthopaedics, Stanmore Campus, \\ London, UK \\ ${ }^{2}$ UCL, Eastman Dental Institute, Division of Biomaterials and Tissue Engineering, 256 Gray's Inn Road, \\ London, UK \\ *Both authors contributed equally to the preparation of the manuscript.
}

\begin{abstract}
Topographic features are well known to influence cell behaviour and can provide a powerful tool for engineering complex, functional tissues. This study aimed to investigate the mechanisms of formation of a stable micro-topography on plastic compressed (PC) collagen gels. The unidirectional fluid flow that accompanies PC of collagen gels creates a fluid leaving surface (FLS) and a non-fluid leaving surface (non-FLS). Here we tested the hypothesis that the resulting anisotropy in collagen density and stiffness between FLS and non-FLS would influence the fidelity and stability of micro-grooves patterned on these surfaces. A pattern template of parallel-aligned glass fibres was introduced to the FLS or non-FLS either at the start of the compression or halfway through, when a dense FLS had already formed. Results showed that both early and late patterning of the FLS generated grooves that had depth ( 25 $\pm 7 \mu \mathrm{m}$ and $19 \pm 8 \mu \mathrm{m}$, respectively) and width $(55 \pm 11 \mu \mathrm{m}$ and $50 \pm 12 \mu \mathrm{m}$, respectively) which matched the glass fibre diameter $(50 \mu \mathrm{m})$. In contrast, early and late patterning of the non-FLS gave much wider $(151 \pm 50 \mu \mathrm{m}$ and $89 \pm 14$ $\mu \mathrm{m}$, respectively) and shallower $(10 \pm 2.7 \mu \mathrm{m}$ and $13 \pm 3.5$ $\mu \mathrm{m}$, respectively) grooves than expected. The depth to width ratio of the grooves generated on the FLS remained unaltered under static culture conditions over 2 weeks, indicating that grooves were stable under long term active cell-mediated matrix remodelling. These results indicate that the FLS, characterised by a higher matrix collagen density and stiffness than the non-FLS, provides the most favourable mechanical surface for precise engineering of a stable micro-topography in 3D collagen hydrogel scaffolds.
\end{abstract}

Keywords: Plastic compressed collagen, stable surface topology, micro-moulding, phosphate-based glass fibres.

\#Address for correspondence:

Professor Robert A. Brown

University College London

Tissue Repair and Engineering Centre, Institute of Orthopaedics

Stanmore Campus

London, HA7 4LP, UK

Telephone Number: +2089095845

FAX Number: +2089548560

E-mail: rehkrab@ucl.ac.uk

\section{Introduction}

One of the most direct approaches to manipulate cell behaviour in vitro is to provide them with anisotropic surfaces, capable of orientating or polarising their morphology (Curtis and Riehle, 2001). To date our knowledge of how various topographical features, from micro- to nano-scale, affect cell differentiation, proliferation and morphology is extensive in some areas but incomplete in others, in particular with regards to cell behaviour on patterned surfaces of natural-polymer based scaffolds (Nelson and Tien, 2006).

Among the methods available for introducing topography onto substrate surfaces, photolithography, wet etching, soft lithography and hot embossing are widely used (Folch and Toner, 2000; Falconett et al., 2006). However, many of these methods are designed for patterning glass, silicon, metals or rigid plastics, which are not particularly biomimetic and so less useful for tissue engineering. Since much of our knowledge of cell behaviour on patterned surfaces is based on these stiff, non-bio materials, recent efforts have begun to focus on the ability to produce known patterns on biocompatible and biodegradable substrates with biomimetic stiffness. Hydrogels, for example, can be micro-moulded by polymerisation (with or without cross-linking) against an elastic template with desired pattern. Chitosan, agarose and collagen hydrogels can be patterned in this manner (Wang and Ho, 2004; Nelson et al., 2008). Mata et al. (2009) used a bottom-up approach to micropattern selfassembling peptide amphiphiles, containing cell-adhesive arginine-glycine-aspartic acid-serine sequence. Gels, containing aligned or random nanofibres, were allowed to self-assemble on the polydimethylsiloxane (PMDS) mould and resulted in high resolution nano- and micropatterning. The authors used these scaffolds to study the reaction of human mesenchymal stem cells to nano- and micro- topology. Poly(ethylene glycol) (PEG) hydrogels can be micro-patterned using the method of soft embossing (Kobel et al., 2009). This involves imprinting a patterned template onto a partially-cross-linked hydrogel such that, when the cross-linking is completed, template features are embossed onto the surface of the gel. Researchers used this technique to culture and analyse the response of single stem cells.

Utilisation of surface topography as a means to control cell behaviour in tissue engineered constructs and tissue analogues are already being investigated. For example, Pins et al. (2000) reported patterning of gelatin and collagen membranes with ridges and channels by 


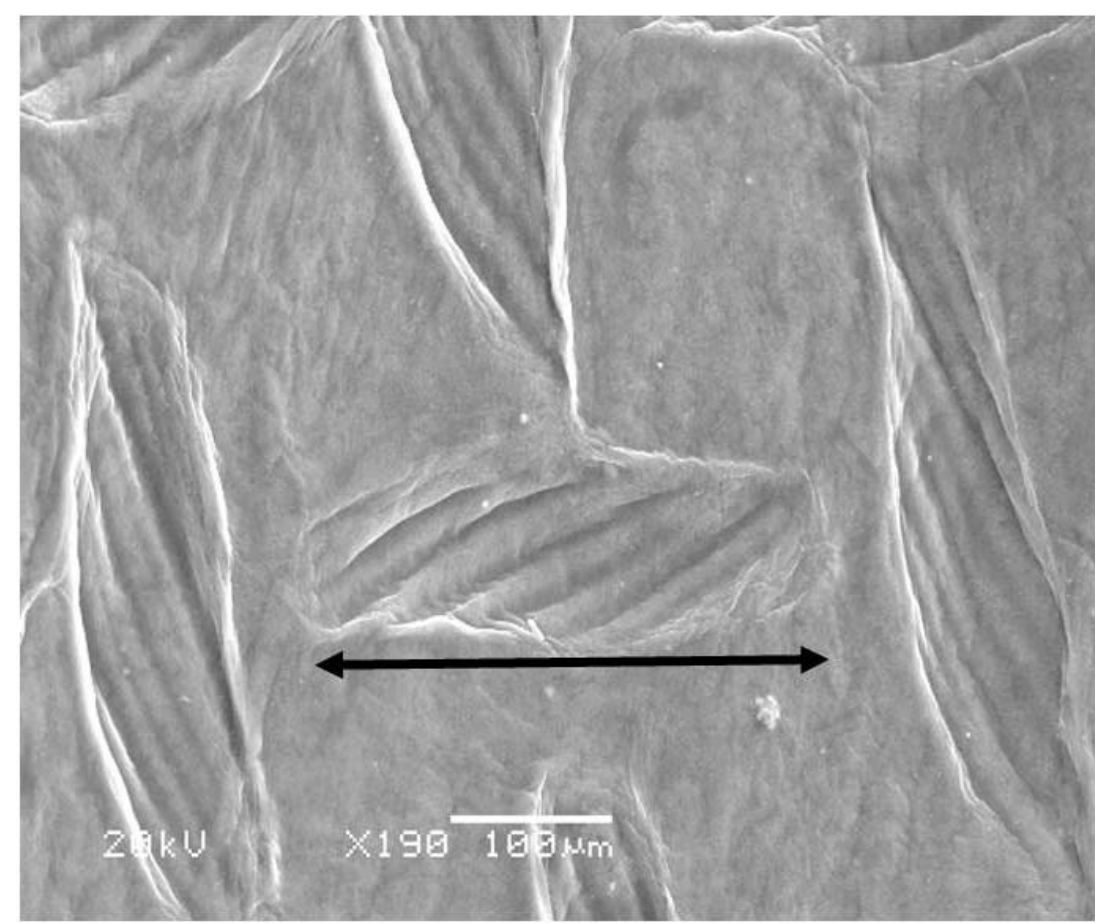

Fig. 1. SEM image of the PC collagen surface with the impression of the nylon mesh which was used as the part of the compression process. Clear negative image of the interwoven fibres is visible (double arrow).

air-drying and cross-linking small quantities of protein solution poured onto a negative PDMS mask. Once laminated onto collagen sponges, these matrices were evaluated as an analogue of the basal lamina in skin. A similar technique was used to micro-pattern chitosan with addition of selective non-adhesive regions for cellpatterning and micro-patterning of collagen films for intestinal tissue engineering (Wang et al., 2010). However, in order to acquire and stabilise the surface topology these methods require cross-linking of the material, making the techniques cell toxic, therefore not allowing for seeding cells within the construct, a pre-requisite for $3 \mathrm{D}$ tissue engineering (although cells can be seeded onto the construct surface once patterning is completed). The present report describes the development of a method to overcome this obstacle.

While hydrogels represent cell-friendly, biomimetic scaffolds, their high water content effectively reduces their mechanical properties, which limits their applicability to tissue engineering. Brown et al. (2005) developed a method termed plastic compression (PC) that allows rapid, cell-independent fabrication of dense, tissue-like collagen scaffolds. It uses rapid, uniaxial expulsion of water from hyper-hydrated collagen gels to generate controlled-density 3D tissue constructs in minutes (Brown et al., 2005). Cells are seeded within the scaffold prior to compression and the process does not affect cell viability. Once the construct is fabricated, different cell-types (e.g. epithelial cells) can be seeded onto its surface. This technology has been proposed for a number of tissue engineering applications, such as skin (Ananta et al., 2009; Hu et al., 2010), cornea (Levis et al., 2010), bone (Pedraza et al., 2010), bladder (Micol et al., 2011) and spinal cord repair (East et al., 2010), together with basic research in tissue interfaces and vascularisation strategies (Hadjipanayi et al., 2009a; Cheema et al., 2010), oxygen diffusion (Cheema et al., 2008, 2009) and cell behaviour in dense collagen matrices (Hadjipanayi et al., 2009b; Serpooshan et al., 2011). Furthermore, use of this material as a peripheral nerve repair conduit is currently under investigation.

In the original study describing the process of $\mathrm{PC}$, the authors had noted that the surface of compressed collagen constructs had a stable embossed pattern of the nylon mesh (with woven fibres of dimensions ranging from 1 to 100 $\mu \mathrm{m})$ (Fig. 1), which was used as a support element during compression. This suggested that it would be possible to introduce controlled topographical features onto the surface of the constructs by impressing a negative template of known geometry and dimensions. For the purpose of this study, we chose parallel-aligned, evenly spaced glass fibres, whose diameter and spacing can be easily controlled during the manufacture process (Ahmed et al., 2004).

The first part of this study was to develop the optimal method for introducing faithful topography on the construct's surface and to understand the mechanisms mediating this process. It was previously shown that the unidirectional flow of fluid during plastic compression produces an asymmetric layer structure of microlamellae throughout the body of the collagen hydrogel (perpendicular to fluid flow), with the most dense layer formed closest to the fluid leaving surface (FLS) (Brown et al., 2005; Hadjipanayi et al., 2011). This anisotropy in collagen density (and by extrapolation matrix stiffness), as reported by Hadjipanayi et al. (2009c), between the top 
(non-fluid leaving surface (non-FLS)) and bottom (FLS) of the gel, could potentially affect the outcome of patterning. On this basis we used four different experimental set-ups of pattern template embossing, to test the effect of matrix density and stiffness differences at each surface. In the first two set-ups, the pattern template was introduced onto the non-FLS or FLS simultaneously with the compression, while in the latter two set-ups patterning was performed following partial compression, once the two surfaces had been formed. The second part of the study aimed to test the effect of cellular remodelling on the stability of the resulting patterned topography by comparing the dimensions (width and depth) of grooves formed in acellular constructs and constructs seeded with human limbal fibroblasts (prior to patterning), over a two weeks culture period.

\section{Materials and Methods}

\section{Preparation of acellular and cellular collagen gels}

Acellular collagen gels were prepared as described previously (Brown et al., 2005). Briefly, $4 \mathrm{~mL}$ of sterile rattail type I collagen $(2.1 \mathrm{mg} / \mathrm{mL}$ protein in acetic acid (First Link, Birmingham, UK) was mixed with $0.5 \mathrm{~mL}$ of $10 \mathrm{x}$ Minimum Essential Medium (MEM, Gibco, Paisley, UK) and equal volume of Dulbecco's Modified Eagle Medium (DMEM, Sigma, Poole, UK) and neutralised drop-wise using $5 \mathrm{M} \mathrm{NaOH}$. Neutralised collagen solution was kept on ice for $30 \mathrm{~min}$ to degas. For cell-seeded gels, collagen solution was mixed with $0.5 \mathrm{~mL} 10 \mathrm{x}$ MEM, neutralised as above and mixed with $5 \times 10^{5}$ Human Limbal Fibroblasts (HLFs, generous gift from Dr. Hannah Levis, Institute of Ophthalmology, UCL) suspended in $0.5 \mathrm{~mL}$ of DMEM. Gels were cast into rectangular stainless steel moulds (30 x $20 \times 7 \mathrm{~mm}$ ) and allowed to set for $30 \mathrm{~min}$ in a humidified atmosphere at $37^{\circ} \mathrm{C}$.

\section{Cell culture}

HLFs were obtained from cadaveric corneal rims with appropriate research consent and ethical permission from the Research Ethics Committee (UK) (Levis et al., 2010). Explants were cultured on a tissue culture plastic in DMEM-Glutamax supplemented with $1 \%$ antibioticantimycotic (Invitrogen, Paisley, UK) and $10 \%$ adult bovine serum (Sigma, UK) for up to one month. Expanded cells were cultured in DMEM supplemented with $1 \%$ penicillin-streptomycin and $10 \%$ foetal calf serum.

\section{Glass fibre template preparation}

Phosphate-based glass fibres were prepared as described previously (Ahmed et al., 2004). Briefly, glass of composition $0.5\left(\mathrm{P}_{2} \mathrm{O}_{5}\right): 0.3(\mathrm{CaO}): 0.17\left(\mathrm{Na}_{2} \mathrm{O}\right): 0.3\left(\mathrm{Fe}_{2} \mathrm{O}_{3}\right)$ was melted in a furnace at $1050{ }^{\circ} \mathrm{C}$ over a custom-made fibre-drawing rig. Rotation speed of the drum allows control over fibre diameter, while lateral displacement of the drum with time allows control of the spacing between the fibres. As shown by Abou Neel (2006), a fibre-collecting drum, moving around its axis with rotating speed of 100 RPM and horizontally along its axis with a step of $50 \mathrm{~Hz}$ will result in average fibre diameter of $50 \pm 8 \mu \mathrm{m}$ with spacing of approximately $100 \mu \mathrm{m}$ between the fibres. Fibres with a diameter of $70 \pm 12 \mu \mathrm{m}$ were used when stability of the pattern was determined in the cell-seeded constructs.

To form a pattern template, fibres were lifted from the drum by placing two strips of adhesive tape perpendicular to the direction of the fibres on the drum, with a spacing of $20 \mathrm{~mm}$ (equal to the short axis of the mould used to form the collagen gel). Each pattern template contained 20 fibres on average. When used in sterile conditions, fibres were UV sterilised for $30 \mathrm{~min}$ on each side.

\section{Experimental designs for construct patterning}

In order to determine a way to introduce stable topographical features onto PC collagen constructs and investigate the mechanisms of such patterning, the following experimental set-ups were investigated:

1. Simultaneous plastic compression (PC) and patterning:

1a. PC + Pattern on the FLS

1b. PC + Pattern on the non-FLS

2. Consecutive $\mathrm{PC}$ and patterning:

2a. PC, then Pattern on the FLS

2b. PC, then Pattern on the non- FLS

Schematic representation of experimental set-ups is illustrated in Fig. 2.

For set-up 1a (Fig. 2a), the template of glass fibres was placed on three sheets of blotting paper (Whatman 1, Whatman, Maidstone, UK). Set collagen gel was then transferred onto the fibres, covered by a glass slide and compressed under fixed mechanical loading for $5 \mathrm{~min}$, as per standard protocol described by Brown et al. (2005).

In protocol $1 \mathrm{~b}$ (Fig. 2b), collagen gel was placed in the same manner onto the blotting elements and the glass fibre template was positioned on top of the gel, which was then compressed for $5 \mathrm{~min}$ as above.

In protocols $2 \mathrm{a}$ and $\mathrm{b}$ (Fig. $2 \mathrm{c}$ and d), gels were precompressed on the blotting paper for $2.5 \mathrm{~min}$. Similarly to set-up 1, in set-up 2a, pre-compressed gel was lifted from the blotting paper and placed on the pattern template facing the FLS (i.e. the bottom surface). In set-up $2 b$, the glass fibre template was placed on the top surface (non-FLS) of pre-compressed gel.

All constructs after assembly were left in phosphatebuffered saline (PBS) overnight and fixed the following day in either $10 \%$ neutral formalin solution for histological examination or $2.5 \%$ glutaraldehyde for scanning electron microscopy (SEM) imaging.

\section{Staining and image analysis}

Wax-embedded constructs were sectioned in a transverse plane at a thickness of $12 \mu \mathrm{m}$, and mounted onto glass slides. Acellular samples were stained with Picrosirius Red, cellular constructs were stained using haematoxylin and eosin. Sections were viewed by light microscope (Zeiss, Jena, Germany) and digital images taken (AxioCam, Zeiss, Germany) and used for further analysis (AxioPlan software). Width and depth of each microgroove (for all experimental set-ups) was measured from the histological images of the patterned constructs. Width was measured as the distance between two points on opposite sides in the widest part of the groove; depth was measured as the length of a perpendicular line drawn from the centre of the 'width' line to the bottom of the groove. For each experimental 


\section{a. FLS patterning}
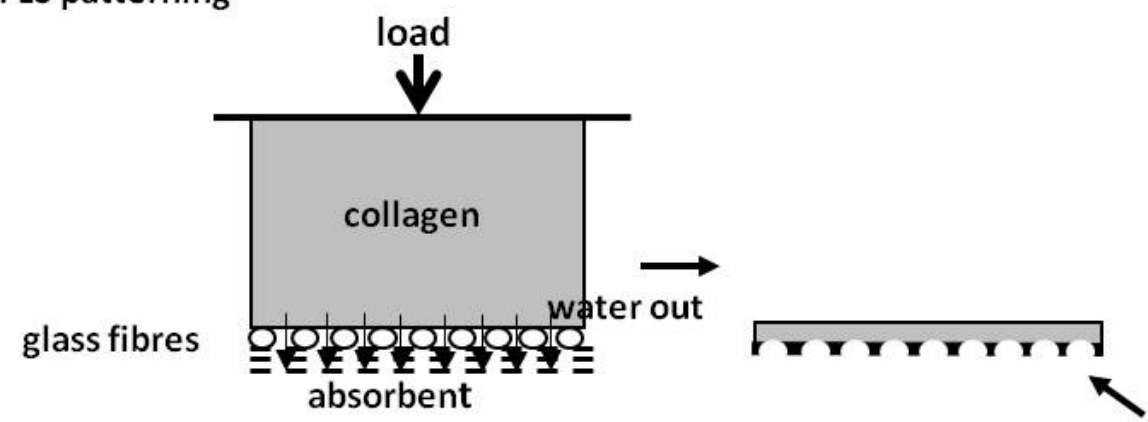

FLS

\section{b. $\mathrm{nFLS}$ patterning}
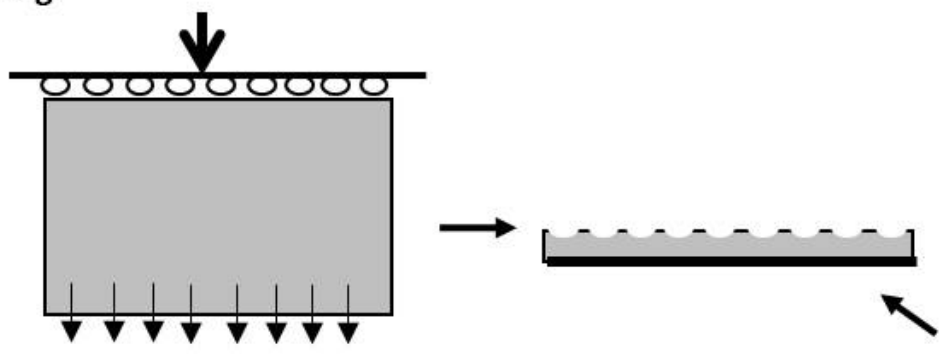

c. part FLS patterning
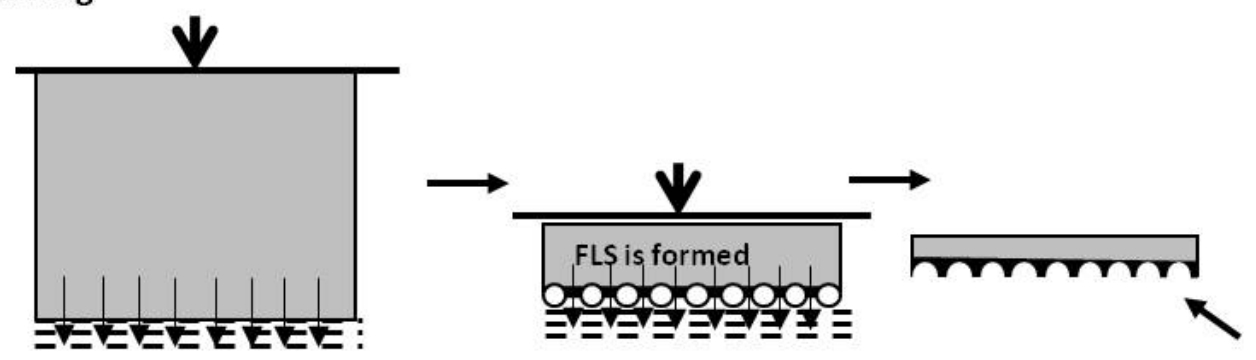

FLS

\section{d. part $\mathrm{nFLS}$ patterning}
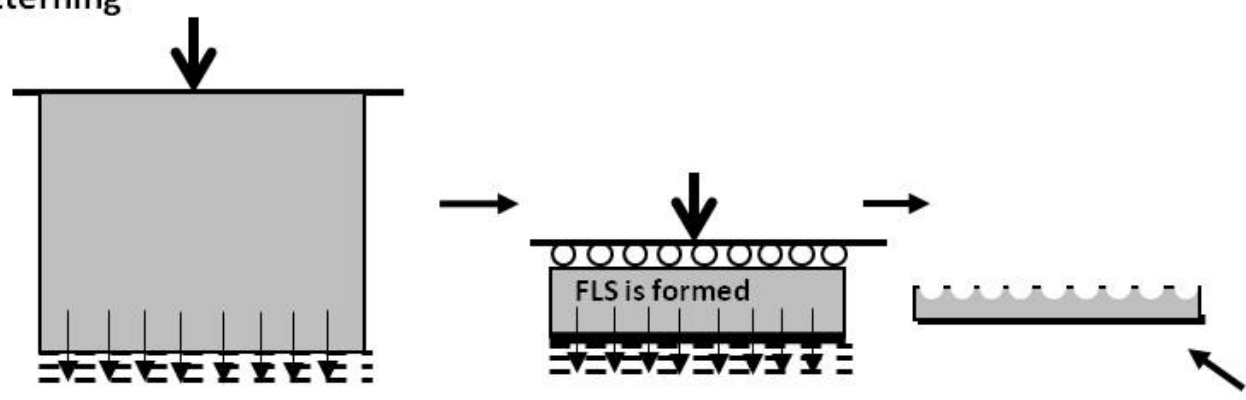

Fig. 2. Schematic illustration of the four experimental set-ups used. Simultaneous patterning (embossing of pattern template of glass fibres) of the FLS with compression (a), simultaneous patterning of the non-FLS with compression (b), consecutive patterning of FLS after partial $(2.5 \mathrm{~min})$ compression (c), and consecutive patterning of non-FLS after partial (2.5 min) compression (d).

design three samples were tested $(n=3)$ with a total of 30 grooves analysed for each condition.

For SEM imaging, constructs were fixed in $2.5 \%$ glutaraldehyde, then dehydrated in ascending alcohol series, fractured perpendicular to the direction of the pattern to reveal the inner structure of the construct and show microgrooves in transverse view, mounted on aluminium stubs and spatter coated with platinum alloy before viewing using a Jeol SE 5000 (Jeol, Tokyo, Japan) microscope (20 $\mathrm{kV})$.
To qualitatively assess groove $3 \mathrm{D}$ profile, patterned samples were analysed using atomic force microscopy. Samples were dehydrated (see sample preparation for SEM) and five fields of view were randomly selected per construct $(n=4)$ for imaging, using an imaging software (WSxM 2.2., Nanotec Electronica S.L., Madrid, Spain).

\section{Statistical analysis}

Data are represented as mean value $\pm \mathrm{SD}$. Data were subjected to one-way analysis of variance (ANOVA), 

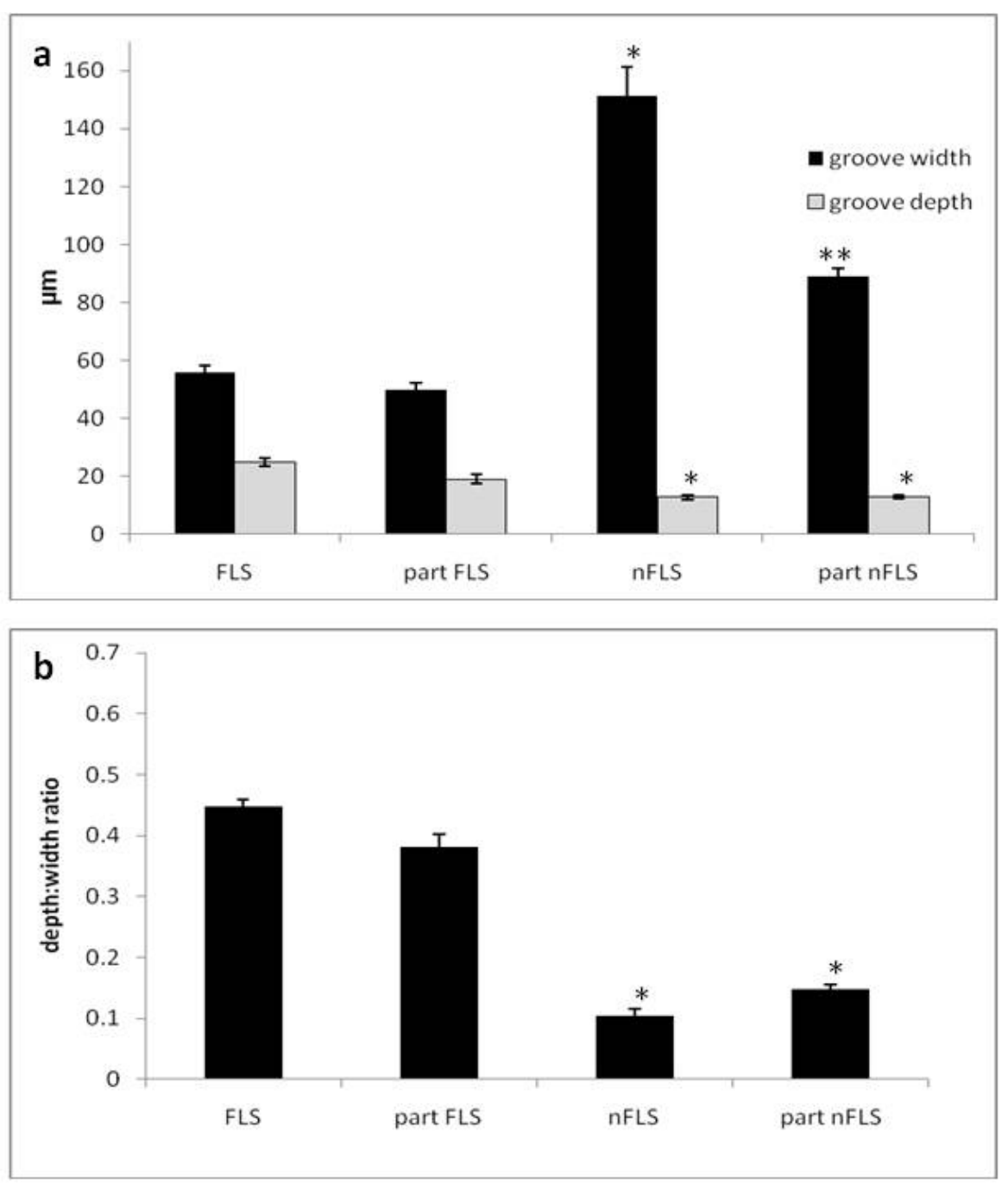

Fig. 3. (a) Plot of mean width and depth of grooves on the surface of PC collagen constructs produced by patterning the FLS throughout compression (FLS), patterning the FLS following partial compression (part FLS), patterning the non-FLS throughout compression (nFLS), and patterning the non-FLS following partial compression (part nFLS). Data were obtained through analysis of histological images of construct cross-sections ( $n=30$ for each condition). (b) Plot of patterning coefficients (groove depth:width ratio) for the same experimental set-ups shown in (a). $* p<$ 0.05 compared to FLS and part FLS, $* * p<0.05$ compared to FLS, part FLS and non-FLS.

confidence interval set at $p<0.05$. Where significant difference between groups was found, Tukey HSD posthoc test was used to identify pairs where difference was significant, confidence interval was set as $p<0.05$.

\section{Results}

Since plastic compression of collagen hydrogels is known to result in development of collagen density and stiffness asymmetry between the FLS and non-FLS (Brown et al., 2005; Hadjipanayi et al., 2011), we first tested the hypothesis that the two gel surfaces (bottom and top, respectively) would have different pattern forming/ retaining ability. This was tested directly in the first two experimental set-ups where embossing of the FLS or nonFLS was carried out simultaneously with the compression
(Fig. 2a and b). As shown in Fig. 3a, embossing of the FLS by placing the pattern template between the gel and absorbent (Fig. 2a) resulted in formation of microgrooves which were $55 \pm 11 \mu \mathrm{m}$ wide and $25 \pm 7 \mu \mathrm{m}$ deep, which matched the diameter of the glass fibres $(50 \pm 14 \mu \mathrm{m})$ used as a patterning template. In contrast, when the template was pressed onto the non-FLS (Fig. 2b), resulting grooves were $151 \pm 50 \mu \mathrm{m}$ wide and $10 \pm 2.7 \mu \mathrm{m}$ deep (Fig. 3a). SEM analysis of the surface of patterned gels showed regularly spaced, parallel running grooves, while confirming that grooves formed by patterning the FLS were deeper and narrower than grooves formed by patterning the nonFLS (Fig. 4a and b). This difference was also evident in histological images of cross-sections of patterned gels (Fig. 5a and b).

Once it was established that patterning on the FLS produced the most faithful topography, we tested the 
a
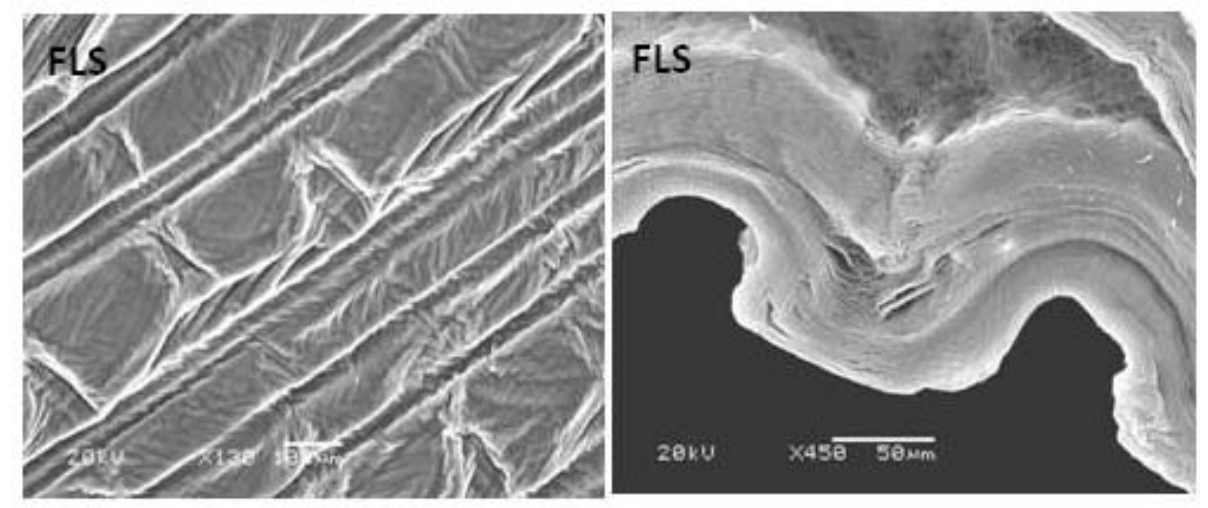

b
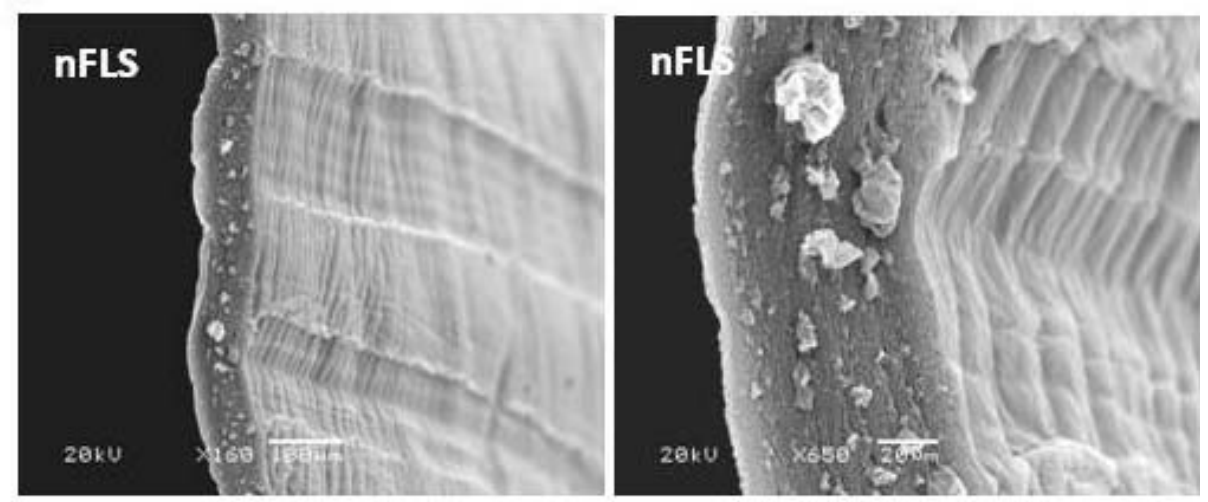

C
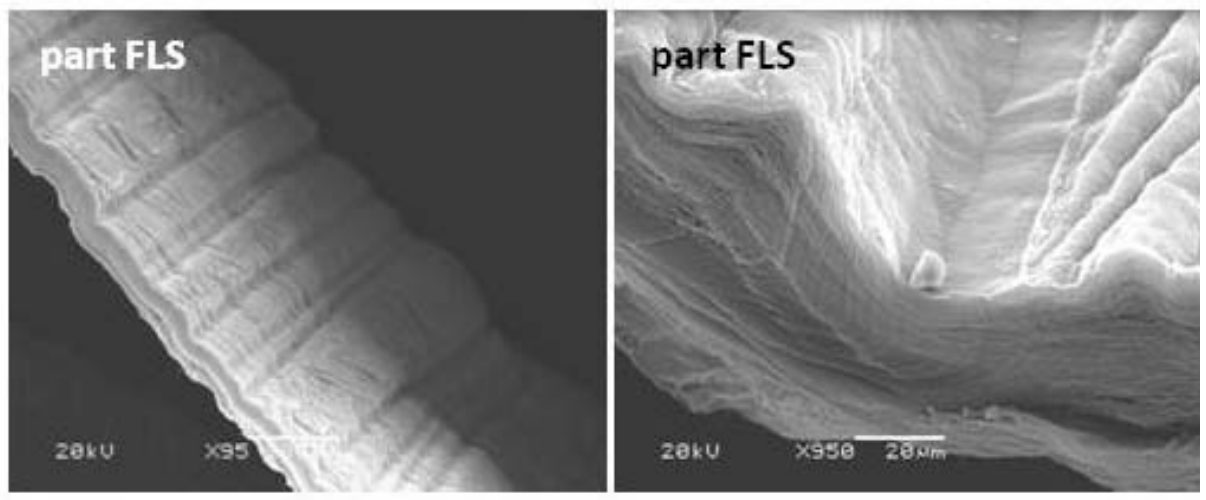

d
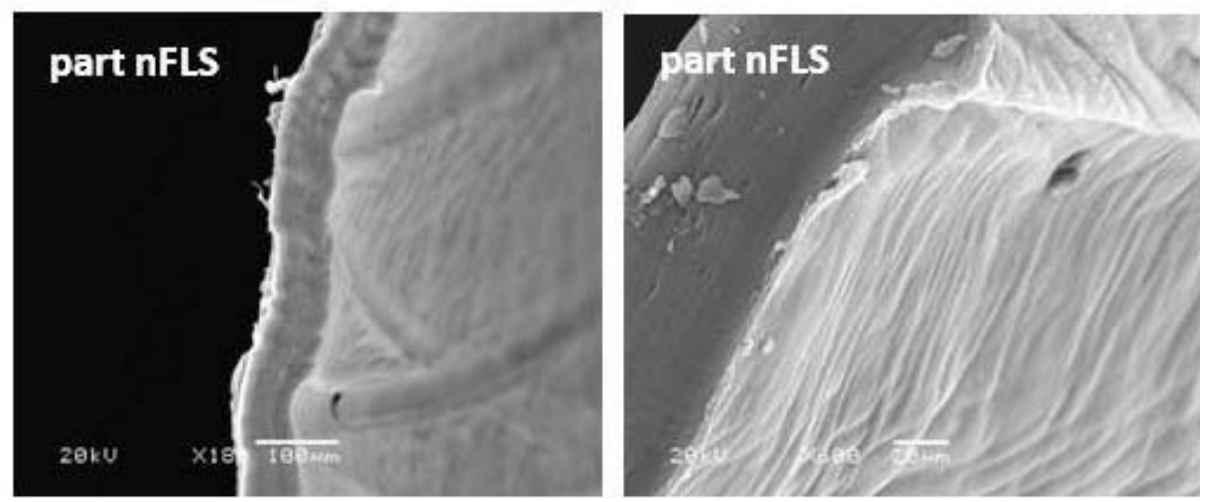

Fig. 4. Representative SEM images of PC collagen constructs patterned simultaneous to the compression on the FLS (a) and non-FLS (b), or consecutive to partial compression on the FLS (c) and non-FLS (d). The left column shows images of the construct surface, while the right column shows the cross-sectional profile of the grooves. 
a

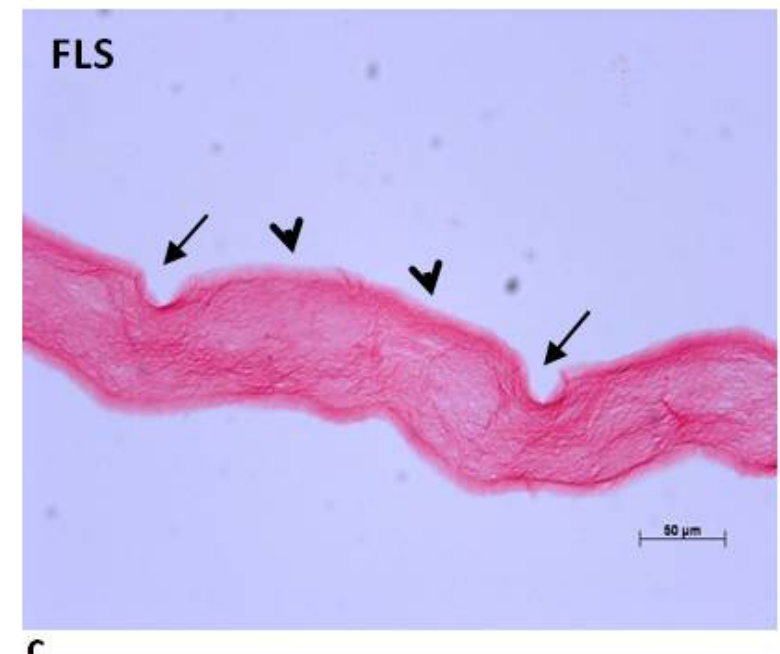

C

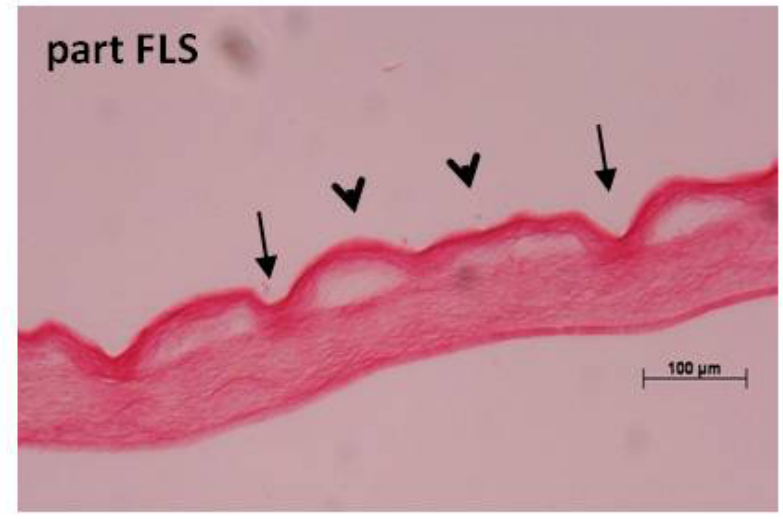

b

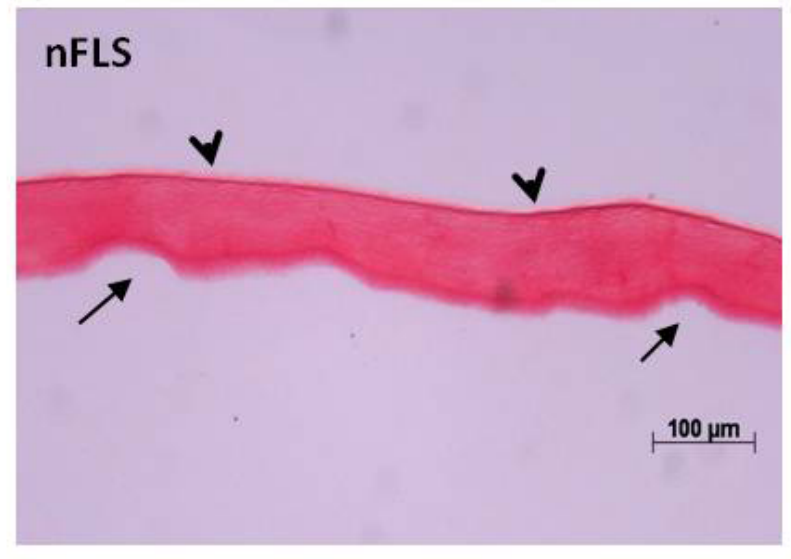

d

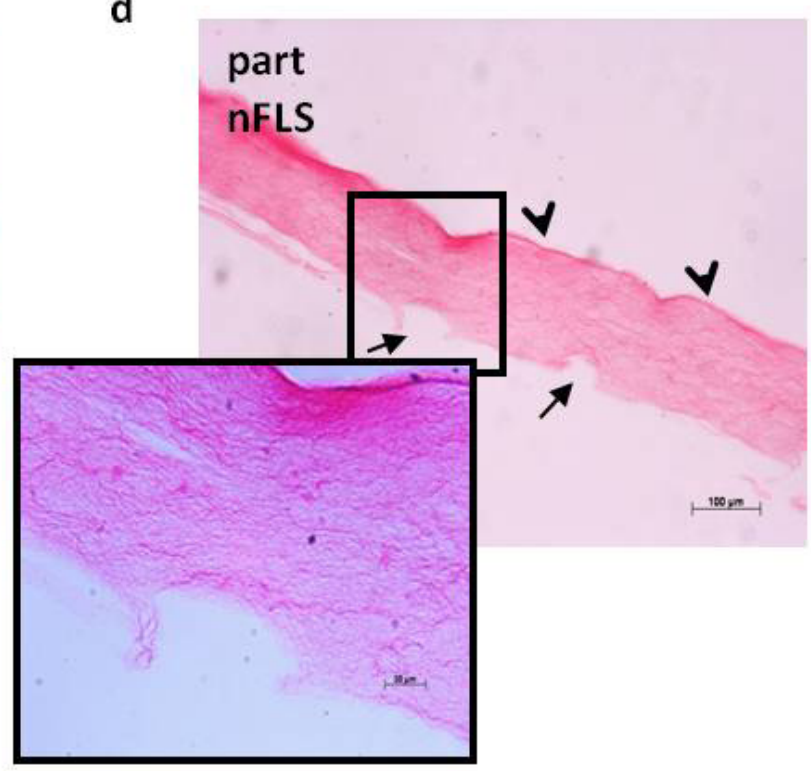

Fig. 5. Representative histological images of the PC collagen constructs patterned simultaneous to the compression on the FLS (a) and non-FLS (b), or consecutive to partial compression on the FLS (c) and non-FLS (d). Sections were stained with Sirius Red to emphasise collagen distribution through the bulk of the construct. Arrows indicate grooves, arrowheads indicate the fluid leaving surface. Insert - higher magnification of the highlighted region.

effect of pressing the pattern template on the FLS of precompressed gels, i.e. patterning on a pre-formed FLS (Fig. 2c), which would be predictably denser and stiffer than the FLS of uncompressed gels. Mean groove width in this case was $50 \pm 12 \mu \mathrm{m}$ with a mean depth of $19 \pm 8 \mu \mathrm{m}$ (Fig. 3a). Importantly, there was no significant difference in either groove width or depth between patterning on a pre-formed FLS and carrying out the patterning simultaneously with the compression from the start (Fig. 3a). SEM analysis showed a well-defined pattern of parallel running, narrow and deep grooves on the FLS of pre-compressed gels (Fig. 4c).

We finally tested whether pressing the template onto the non-FLS of pre-compressed gels (Fig. 2d) would improve the patterning ability on this surface. Since precompression evidently resulted in an increase in collagen density and stiffness throughout the body of the gel, i.e. at the non-FLS as well as at the FLS (note: the increase in collagen density at the non-FLS would predictably be lower compared to the FLS (Hadjipanayi et al., 2011), the basic hypothesis here was that pressing the template onto a precompressed non-FLS would improve the fidelity of groove dimensions, in relation to carrying out the patterning during the compression on this surface. Grooves produced using this method were $89 \pm 14 \mu \mathrm{m}$ wide and $13 \pm 3.5 \mu \mathrm{m}$ deep (Fig. 3a). Therefore, while this set-up failed to generate deeper grooves, it significantly reduced groove width $(p<$ $0.05)$ compared to the pattern on the non-FLS. However, groove depth remained significantly lower compared to the depth of grooves produced by patterning on the FLS (either condition) $(p<0.05)$. SEM (Fig. $4 \mathrm{c}$ and $\mathrm{d})$ and histological analysis (Fig. 5c and d) confirmed these differences.

As a measure of the accuracy of micro-patterning, a patterning coefficient was calculated for each groove 
a

\section{b}
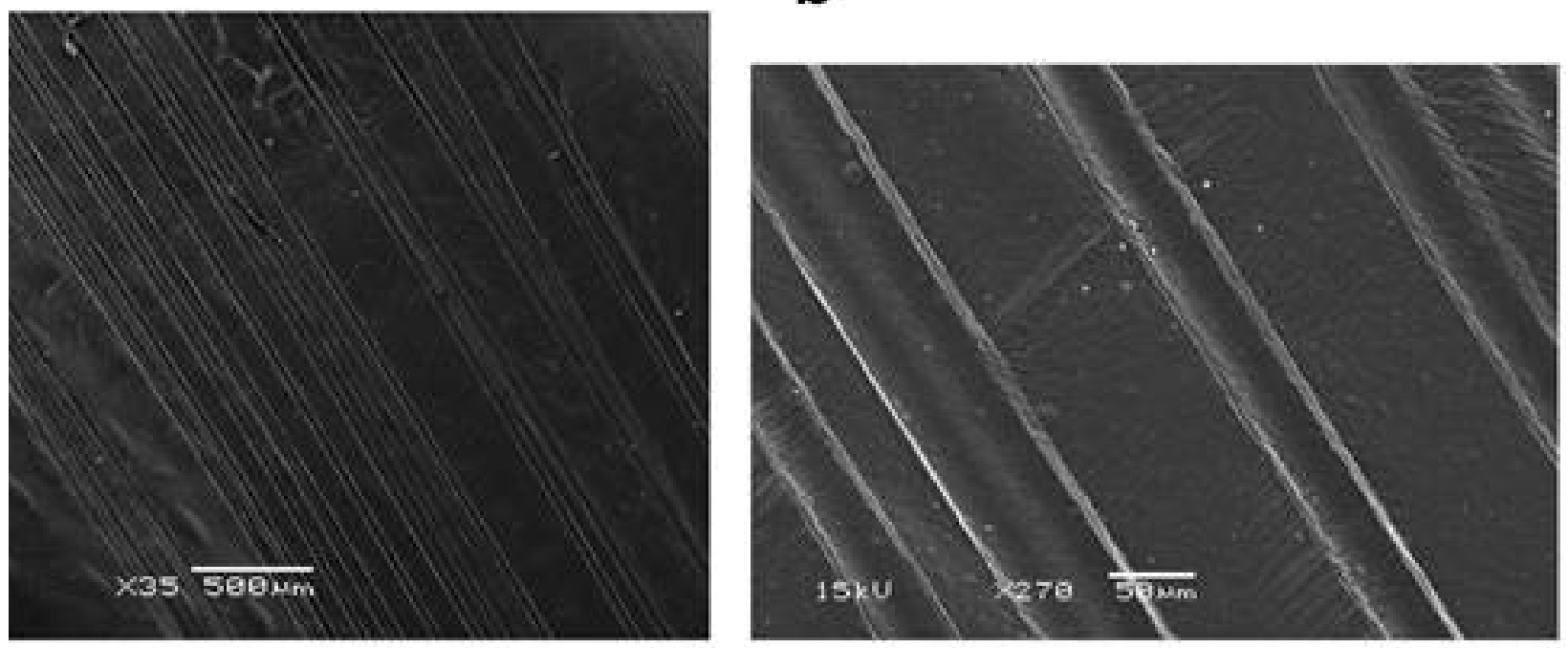

C
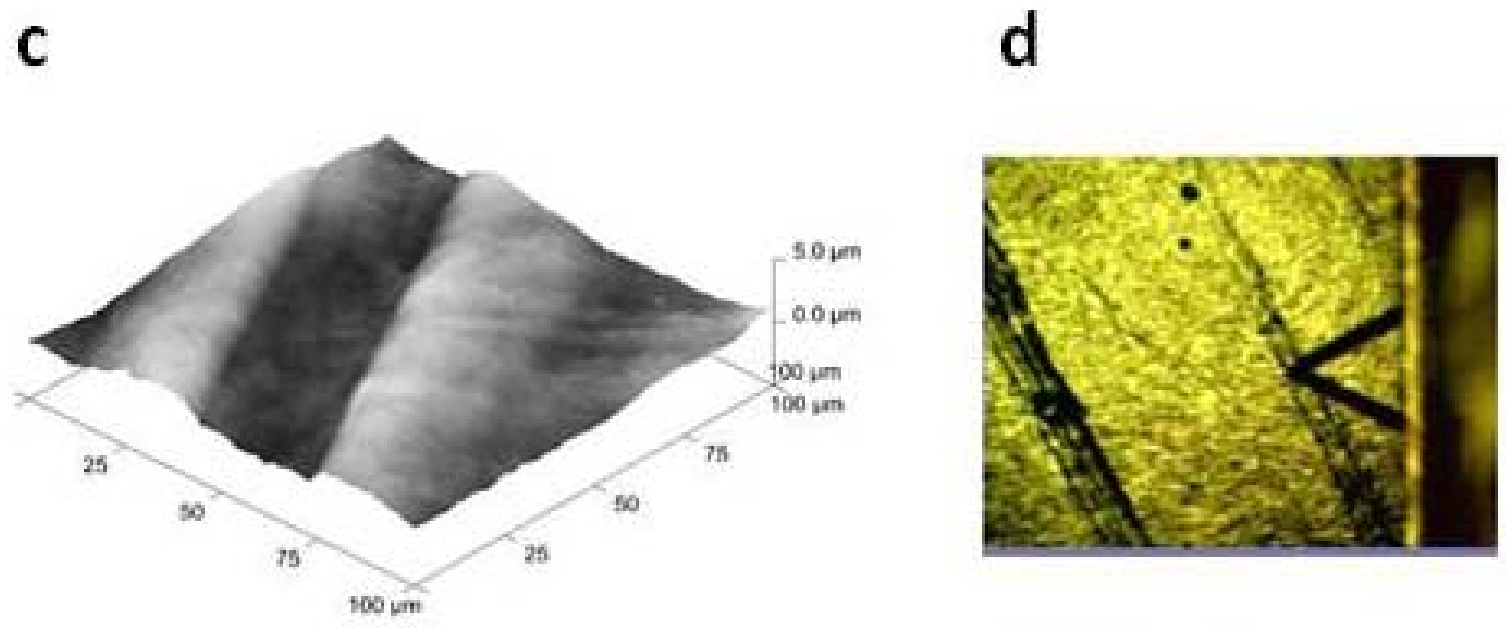

e

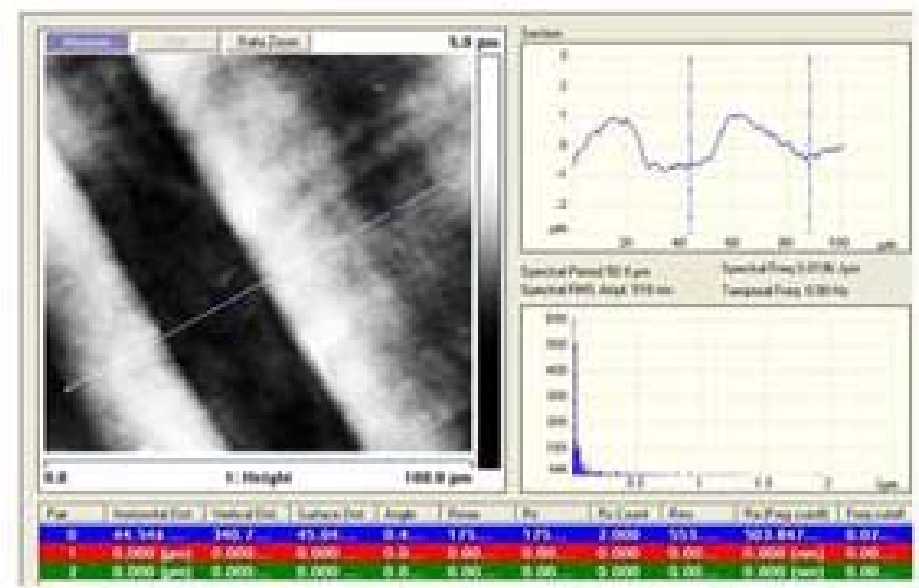

Fig. 6. SEM and AFM analysis of patterned topography. Low (a) and high (b) magnification SEM images of collagen constructs, patterned by pre-compressing collagen gels for $2.5 \mathrm{~min}$ and then introducing a negative pattern template onto non-FLS and compressing for further $2.5 \mathrm{~min}$, showing a regular pattern of grooves and ridges on the construct surface. The 3D profile of patterned grooves was characterised by AFM (c). Panel (d) shows the tip of the AFM probe at a groove's surface. Panel (e) shows a digital snapshot of the imaging software used to analyse groove crosssectional geometry. 


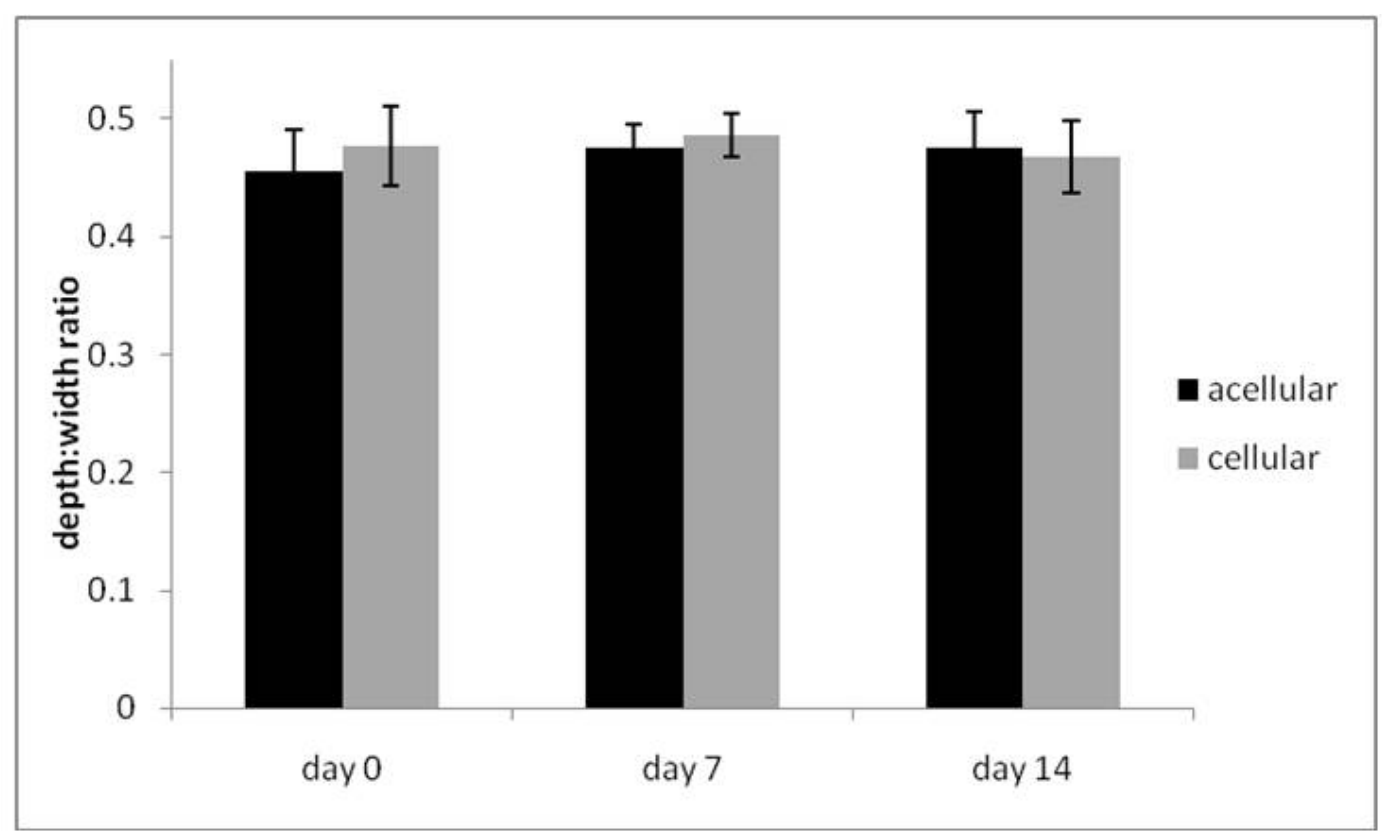

Fig. 7. Plot of patterning coefficients (groove depth:width ratio) of the topographical features (grooves) imprinted onto the FLS of acellular and cell-seeded PC constructs as an indicator of groove stability after long-term (14 d) static culture. Measurements were taken at days 0,7 and $14(n=30)$. Topographical features introduced onto the FLS were permanent and stable under the culture conditions with and without cell-mediated active matrix remodelling.

analysed, as the groove depth to width ratio. This allowed simultaneous assessment of pattern fidelity in the $\mathrm{x}$ - and y-planes of the groove (for width and depth, respectively), which in combination with analysis of grooves from multiple construct cross-sections, i.e. in the z-plane, could enable quantitative assessment of groove 3D profile. A coefficient of 0.5 represented a satisfactory degree of patterning (as it indicated that the glass fibre was impressed at least half-way into the construct, i.e. coefficient was equal to fibre radius:diameter ratio). Mean patterning coefficient for grooves generated by patterning the FLS was $0.45 \pm 0.05$ and $0.38 \pm 0.07$ for simultaneous and consecutive patterning, respectively (Fig. 3b). Patterning of the non-FLS, either simultaneously or consecutive to the compression, resulted in grooves with a significantly lower patterning coefficient of $0.1 \pm 0.06$ and $0.15 \pm 0.04$, respectively (Fig. 3b).

AFM analysis was used to visualise the $3 \mathrm{D}$ profile (cross-sectional border and internal wall structure, Fig. 6d) of patterned grooves, as a complementary measure of the fidelity of micro-patterning in relation to the geometry of the glass-fibres used to create the patterning template. Constructs patterned on the non-FLS after partial compression were chosen for this analysis, as grooves generated using this set-up had a lower patterning coefficient, suggesting a reduced degree of pattern fidelity. Fig. $6 \mathrm{a}$ and $6 \mathrm{~b}$ show that in such constructs grooves were continuous, with a smooth internal wall structure (Fig. 6c) and a symmetric cross-sectional border (Fig. 6e). This indicated that while patterning on the non-FLS had resulted in limited retention of groove depth, the grooves formed faithfully recapitulated the cylindrical geometry of the glass fibre.
Since the ultimate aim of topographic patterning is control of cell morphology/function, the stability of grooves subjected to active cellular remodelling was tested in constructs seeded with Human Limbal Fibroblasts and cultured for $14 \mathrm{~d}$. Constructs were produced by patterning on the FLS simultaneous to the compression (Fig. 2a), as these had the grooves with the highest patterning coefficient. As shown in Fig. 7 there was no significant difference in mean patterning coefficient of grooves generated on acellular and cell-seeded constructs, over 14 $\mathrm{d}$ of culture, suggesting that active cellular remodelling had not altered the groove 3D profile/geometry. Importantly, in acellular constructs the mean patterning coefficient remained stable over $14 \mathrm{~d}$ of culture (as measured at day 0,7 and 14), indicating minimal passive remodelling (e.g. re-swelling) of the constructs. Histological cross-sectional images of the cellular constructs taken on days 1 and 14 (Fig. 8a and b) confirmed the presence of stable grooves, while showing signs of collagen matrix remodelling (seen as matrix-sparse areas) by the resident cells at the end of the culture period, giving the construct a characteristic 'lacy' appearance.

\section{Discussion}

It is increasingly appreciated that the topography of a tissue-engineered construct at the micrometre scale is critical to controlling many cell functions. It is well established, for example, that surface anisotropy and microstructure have a profound effect on cell alignment and differentiation (Clark et al., 1987, 1990; Pins et al., 2000; 


\section{a}
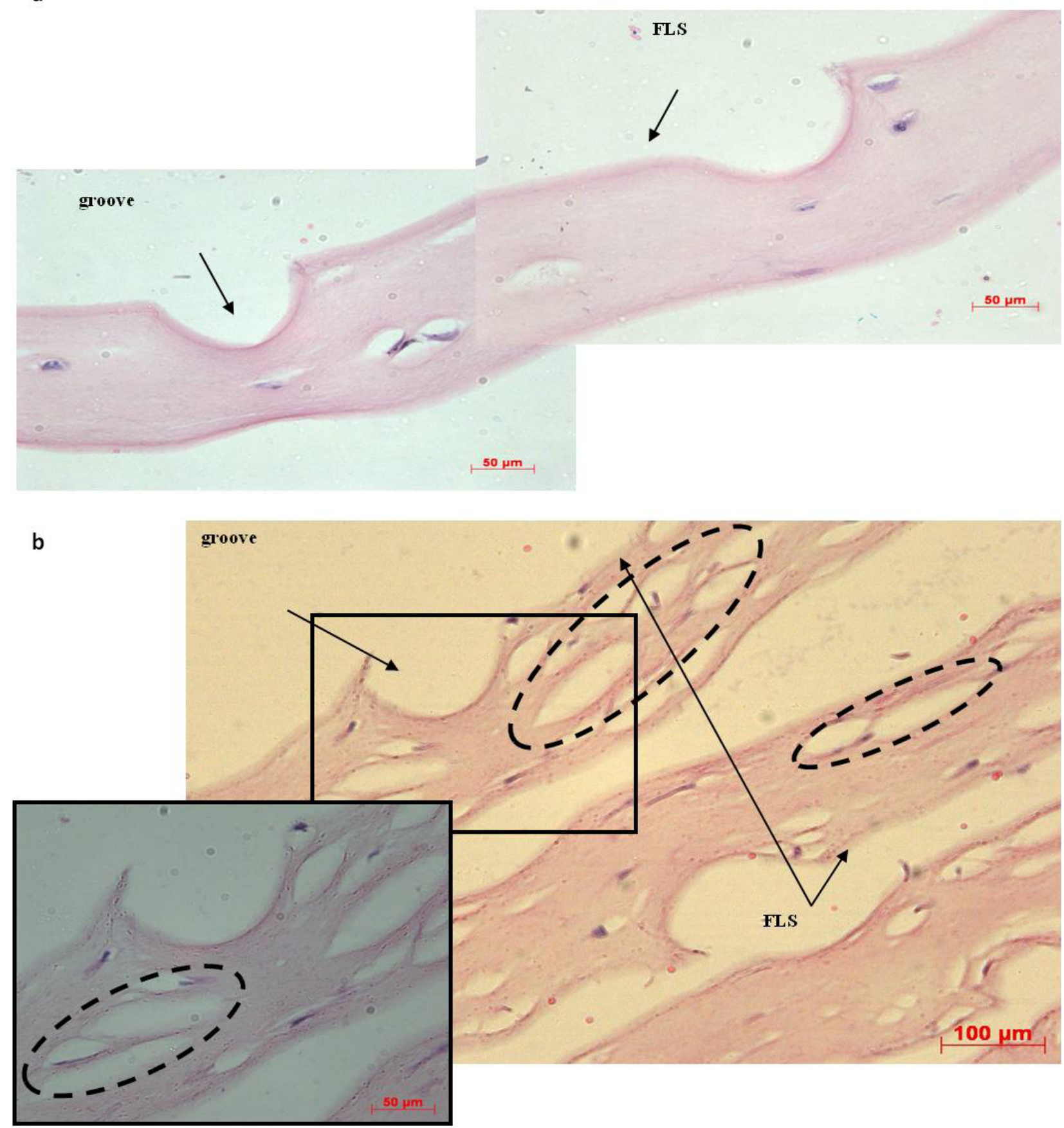

Fig. 8. Representative histological images of the cell-seeded (human limbal fibroblasts) PC collagen constructs with grooves introduced onto the fluid leaving surface (FLS). Images were taken after $1 \mathrm{~d}$ (a) and $14 \mathrm{~d}$ (b) of culture. The 'lacy' appearance of the collagen (dashed ovals) in (b) is characteristic of PC collagen constructs which have previously been identified to have undergone matrix remodelling by the resident cells with time in culture. Note that this pattern (body of the construct) is distinct from that of patterned grooves (surface of the construct). Insert higher magnification of the highlighted region.

Teixeira et al., 2003, 2004; Downing et al., 2004; Vernon et al., 2005). Indeed, some studies show that the effects of topological features on cells extend beyond the single layer and affect cells that are not in direct contact with the surface (Mudera et al., 2000; Guillemette et al., 2009; Then et al., 2011). Consequently, accurate, predictable and stable topographic patterning is a pre-requisite for next generation studies investigating biomimetic $3 \mathrm{D}$ niches to control, for example, stem cell function and fate (Vazin and Schaffer, 2010), as well as cell-cell/cell-matrix interactions at interfaces (e.g. dermo-epidermal junction). Indeed, Nelson and Tien (2006) pointed out that simply by adding structure it may be possible to improve almost any biomaterial by creating extra cues that influence cell behaviour, making this a favourable strategy to expand the function of a tissue-engineered construct. 
In this study we describe the development of a method for introducing accurate and stable topographical features onto the surface of plastic compressed 3D collagen constructs. The fact that a stable topography can be created in these dense collagen materials is in fact not surprising. The compaction process involves a plastic (i.e. largely irreversible) deformation as fluid is forced out of the collagen fibril network, and predictably the same plastic (non-elastic) deformation should occur at the micron scale around structures pressed into the surface. This process also leaves stable micro-channels running through the bulk of the material where embedded phosphate glass fibres dissolve (Nazhat et al., 2007). However, the fluid flow out of such gels and eventual collagen distribution during PC are by no means homogeneous (Hadjipanayi et al., 2011), and this study clearly shows that topographic patterning can be significantly influenced by these local factors. It is important, then, that we understand the precise effect of matrix density and mechanical properties (e.g. stiffness) on the stability and fidelity of engineered topography.

In this study we investigated the hypothesis that the micro-topography would be more predictable and stable when the patterning template is pressed onto the FLS. Since interstitial fluid is forced out of the collagen gel in one direction in PC, a single FLS is formed. This unidirectional flow generates profound top-bottom anisotropy in the collagen sheet, along with multiple lamellae (Brown et al., 2005; Hadjipanayi et al., 2011). Since the FLS of a collagen gel under compression behaves as an ultrafiltration membrane, it rapidly accumulates a densely packed layer of collagen fibrils, which are left behind as fluid passes through (Hadjipanayi et al., 2011). This contrasts starkly with the non-FLS, which has a much lower collagen density. Importantly, we have shown previously that collagen fibril density correlates closely with the local mechanical stiffness of the material (Hadjipanayi et al., 2009a). Indeed, the mechanism of groove patterning proposed and tested here, namely that increased matrix density and stiffness results in more prominent and stable topographic features, is reminiscent of currently proposed models of wrinkle formation of aged human dermis which has a lower moisture content and elasticity (Flynn et al., 2010).

The results showed that grooves generated on the FLS were far more stable and more faithfully reflected the glassfibre dimensions and geometry than those formed on the non-FLS as indicated by the higher patterning coefficient and morphological evidence (SEM, AFM and histology). In effect, the full diameter (the width of the groove) and curvature of the fibre could be retained in grooves patterned on the FLS. The same was true for grooves generated on the pre-formed FLS. In contrast, when the pattern template was embossed onto the non-FLS, either during compression or consecutively, grooves produced were very shallow (approx. $20 \%$ of the fibre diameter) and almost double in width compared to grooves generated on the FLS. This width to depth discrepancy suggests that grooves in the non-FLS underwent elastic recoil after the fibres were withdrawn. We hypothesise that this is a consequence of the elastic properties of the 'skin-like' surface film of packed collagen fibrils which surrounds the original collagen gel when it is cast (i.e. present on the gel-air casting interface) (Karamichos et al., 2006). On the nonFLS this ordered fibrillar structure will not be substantially changed (i.e. compacted) in collagen density, due to the highly asymmetric fluid movement during compression. Hence, pushing the template fibres into the surface, when embossing the non-FLS, stretches the film around the template, so that borders of the groove are formed, but elastic recoil of the film removes all but a few micrometres of its original depth, while moving the borders further apart. Interestingly, width of the grooves made by this method almost matched the glass fibre circumference (average of $157 \mu \mathrm{m}$ ), which may indicate that fibres initially 'sunk' into the gel and, as compression progressed, borders were moved apart as described above. When pressing the pattern template onto the non-FLS of partially compressed gels, resulting grooves were less wide and marginally deeper than the ones generated in uncompressed gels. This might indicate that in this case the gel body, which became by that time denser after fluid removal, had acquired some of the mechanical properties (e.g. increased stiffness) of the FLS and did not contribute to the elastic recoil in the same extent.

The stable topography patterned with this simple, onestep process reflects the importance of rapid fluid flow through the FLS and around the impervious glass fibres, which not only compact collagen fibrils, but also tends to align them parallel with the flow (Kureshi et al., 2010). Such induced alignment would be expected to be circumferential around the glass fibres, i.e. in the direction of deflected flow. It is proposed that this remodelling of overall fibril orientation contributes strongly to pattern stability by eliminating elastic recoil. This concept suggests that a large part of PC micro-patterning, therefore, is due to controlled fibril remodelling, similar to the process of fibrous material moulding as used in felt goods manufacture. We therefore refer to this process as pattern micro-moulding, rather than using the more general term 'embossing', which would more accurately describe micro-patterning of preformed FLS, where the mechanical properties of the FLS contribute more to pattern formation than fluid flow. Importantly, the results suggest that the higher collagen fibril density and the accompanying increase in matrix stiffness at the FLS and throughout the body of the collagen gel (Hadjipanayi et al., 2011) did not prevent deformation of this surface, indicating that this process operated below the mechanical limit. More precise investigation of FLS mechanical properties is currently under way.

The proposed mechanism of collagen matrix remodelling/moulding for topographic patterning is supported by the observation that generated grooves, moulded into the FLS, were stable over two weeks in culture. Interestingly, over that period cells seeded into the collagen bulk material had already begun to remodel their local matrix as can be seen from the characteristic 'lacy' appearance of the constructs. This is consistent with previous in vitro remodelling reports (Brown et al., 2005; 
Bitar et al., 2008) but implies considerable long-term stability, and so tissue engineering utility, of patterned features.

The current method of surface micro-patterning in $3 \mathrm{D}$ collagen materials is predictable and controllable. It also provides the ability to generate a range of pattern geometries by optimising or minimising fibril remodelling, by controlling fluid flow (Hadjipanayi et al., 2011). In addition, pattern depth could be controlled by changing the initial collagen gel height, and consequently the thickness of the resulting collagen sheet. Importantly, this simple, one-step technique allows patterning of the construct whilst retaining viable, active cells seeded within the dense collagen matrix. Clearly, micro-patterning of biomimetic extracellular matrix has considerable physiological advantage over other, more commonly patterned surfaces, such as polymers or silica. But in addition to this, the present technique provides an attractive alternative to existing methods of surface patterning of soft hydrogels where cell-lethal cross-linking is an essential part of the process, such that cells must be added later (which extends fabrication time, as cells must penetrate and populate the matrix).

In conclusion, this study has investigated the mechanisms by which stable micro-patterns can be formed onto the surface of 3D dense collagen materials. This is a key knowledge, as it paves the way to more precise and controlled engineering of tissue-like collagen constructs with cells in situ. This represents a considerable biomimetic advantage over previous patterning methods which use non-physiological synthetic polymers or cross-linked hydrogels. Importantly, since this process can be carried out on native collagen matrix, it could provide insight as to how fluid flows through natural, living tissues, and how its effect on matrix mechanical properties (e.g. stiffness) works to sculpture the fine local patterns which are known to control cell morphology, function and fate.

\section{Acknowlegements}

We would like to thank TSB-EPSRC for funding, Steve Owen for discussion, and Dr. Laurent Bozek for help with the AFM.

\section{References}

Ahmed I, Lewis M, Olsen I, Knowles JC (2004) Phosphate glasses for tissue engineering: Part 2. Processing and characterisation of a ternary-based $\mathrm{P}_{2} \mathrm{O}_{5}-\mathrm{CaO}-\mathrm{Na}_{2} \mathrm{O}$ glass fibre system. Biomaterials 25: 501-507.

Ananta M, Aulin CE, Hilborn J, Aibibu D, Houis S, Brown RA, Mudera V (2009) A poly(lactic acid-cocaprolactone)-collagen hybrid for tissue engineering applications. Tissue Eng A. 15: 1667-1675.

Abou Neel E (2006) Collagen-phosphate glass fibres for biomedical and tissue engineering applications. $\mathrm{PhD}$ thesis, University College London, UK.

Bitar M, Brown RA, Salih V, Kidane AG, Knowles JC, Nazhat SN (2008) Effect of cell density on osteoblastic differentiation and matrix degradation of biomimetic dense collagen scaffolds. Biomacromolecules 9: 1291-1335.

Brown RA, Wiseman M, Chuo CB, Cheema U, Nazhat SN (2005) Ultrarapid engineering of biomimetic materials and tissues: Fabrication of nano- and microstructures by plastic compression. Adv Funct Mater 15: 1762-1770.

Cheema U, Brown R, Alp B, MacRobert A (2008) Spatially defined oxygen gradients and vascular endothelial growth factor expression in an engineered 3D cell model. Cell Mol Life Sci 65: 177-186.

Cheema U, Hadjipanayi E, Tammi N, Alp B, Mudera V, Brown RA (2009) Identification of key factors in deep $\mathrm{O} 2$ cell perfusion for vascular tissue engineering. Int J Artif Organs 32: 318-328.

Cheema U, Alekseeva T, Abou-Neel EA, Brown RA (2010) Switching off angiogenic signalling: creating channelled constructs for adequate oxygen delivery in tissue engineered constructs. Eur Cell Mater 20: 274-280.

Clark P, Connoly P, Curtis ASG, Dow JAT, Wilkinson CDW (1987) Topographical control of cell behaviour: I. Simple step cues. Development 99: 439-448.

Clark P, Connoly P, Curtis ASG., Dow JAT, Wilkinson CDW (1990) Topographical control of cell behaviour: II. multiple grooved substrata. Development 108: 635-644.

Curtis A, Riehle M (2001) Tissue engineering: the biophysical background. Phys Med Biol 46: R47-65.

Downing BR, Cornwell K, Toner M, Pins GD (2005) The influence of microtextured basal lamina analog topography on keratinocyte function and epidermal organization. J Biomed Mater Res A 72: 47-56.

East E, de Oliveira DB, Golding JP, Phillips JB (2010) Alignment of astrocytes increases neuronal growth in three-dimensional collagen gels and is maintained following plastic compression to form a spinal cord repair conduit. Tissue Eng A. 16: 3173-3184.

Falconnet D, Csucs G, Grandin HM, Textor M (2006) Surface engineering approaches to micropattern surfaces for cell-based assays. Biomaterials 27: 3044-3063.

Flynn C, McCormack BA (2010) Simulating the wrinkling and aging of skin with a multi-layer finite element model. J Biomech 43: 442-448.

Folch A, Toner M (2000) Microengineering of cellular interactions. Annu Rev Biomed Eng 2: 227-256.

Guillemette MD, Cui B, Roy E, Gauvin R, Glasson CJ, Esch MB, Carrier P, Deschambeault A, Dumoulin M, Toner M, Germain L, Veres T, Auger FA (2009) Surface topography induces 3D self-orientation of cells and extracellular matrix resulting in improved tissue function. Integr Biol 1: 196-204.

Hadjipanayi E, Brown RA, Mudera V (2009a) Interface integration of layered collagen scaffolds with defined matrix stiffness: implications for sheet-based tissue engineering. J Tissue Eng Regen Med 3: 230-241.

Hadjipanayi E, Mudera V, Brown RA (2009b) Guiding cell migration in 3D: a collagen matrix with graded directional stiffness. Cell Motil Cytoskeleton 66: 121-128.

Hadjipanayi E, Mudera V, Brown RAJ (2009c) Close dependence of fibroblast proliferation on collagen scaffold matrix stiffness. Tissue Eng Regen Med 3: 77-84.

Hadjipanayi E, Ananta M, Binkowski M, Streeter I, Lu Z, Cui ZF, Brown RA, Mudera V (2011) Mechanisms 
of structure generation during plastic compression of nanofibrillar collagen hydrogel scaffolds: towards engineering of collagen. J Tissue Eng Regen Med 5: 505 519.

Hu K, Shi H, Zhu J, Deng D, Zhou G, Zhang W, Cao Y, Liu W (2010) Compressed collagen gel as the scaffold for skin engineering. Biomed Microdevices 12: 627-635.

Karamichos D, Brown RA, Mudera V (2006) Complex dependence of substrate stiffness and serum concentration on cell-force generation. J Biomed Mater Res A. 78: $407-$ 415.

Kobel S, Limacher M, Gobaa S, Laroche T, Lutolf MP (2009) Micropatterning of hydrogels by soft embossing. Langmuir 25: 8774-8779.

Kureshi A, Cheema U, Alekseeva T, Cambrey A, Brown $\mathrm{R}$ (2010).Alignment hierarchies: engineering architecture from the nanometre to the micrometre scale. J R Soc Interface 7 Suppl 6: S707-716.

Levis HJ, Brown RA, Daniels JT (2010) Plastic compressed collagen as a biomimetic substrate for human limbal epithelial cell culture. Biomaterials 31: 7726-7737.

Mata A, Hsu L, Capito R, Aparicio C, Henrikson K, Stupp SI (2009) Micropatterning of bioactive selfassembling gels. Soft Matter 5: 1228-1236.

Micol LA, Ananta M, Engelhardt EM, Mudera VC, Brown RA, Hubbell JA, Frey P (2011) High-density collagen gel tubes as a matrix for primary human bladder smooth muscle cells. Biomaterials 32: 1543-1548.

Mudera VC, Pleass R, Eastwood M, Tarnuzzer R, Schultz G, Khaw P, McGrouther DA, Brown RA (2000) Molecular responses of human dermal fibroblasts to dual cues: contact guidance and mechanical load. Cell Motil Cytoskeleton 45: 1-9.

Nazhat S.N., Neel EA, Kidane A, Ahmed I, Hope C, Kershaw M, Lee PD, Stride E, Saffari N, Knowles JC, Brown RA (2007) Controlled microchannelling in dense collagen scaffolds by soluble phosphate glass fibers. Biomacromolecules 8: 543-551.

Nelson C.M., Tien J (2006) Microstructured extracellular matrices in tissue engineering and development. Curr Opin Biotechnol 17: 518-523.

Nelson C.M, Inman JL, Bissell MJ (2008) Threedimensional lithographically defined organotypic tissue arrays for quantitative analysis of morphogenesis and neoplastic progression. Nat Protoc 3: 674-678.

Pedraza CE, Marelli B, Chicatun F, McKee MD, Nazhat SN (2010) An in vitro assessment of a cell-containing collagenous extracellular matrix-like scaffold for bone tissue engineering. Tissue Eng A 16: 781-793.

Pins GD, Toner M, Morgan JR (2000) Microfabrication of an analog of the basal lamina: biocompatible membranes with complex topographies. FASEB J 14: 593-603.
Serpooshan V, Muja N, Marelli B, Nazhat SN (2011) Fibroblast contractility and growth in plastic compressed collagen gel scaffolds with microstructures correlated with hydraulic permeability. J Biomed Mater Res A 96: 609-620

Teixeira AI, Abrams GA, Bertics PJ, Murphy CJ, Nealey PF (2003) Epithelial contact guidance on welldefined micro- and nanostructured substrates. J Cell Sci 116: $1881-1892$.

Teixeira AI, Nealey PF, Murphy CJ (2004) Responses of human keratocytes to micro- and nanostructured substrates. J Biomed Mater Res A 71: 369-376.

Then KY, Yang Y, Ahearne M, El Haj AJ (2011) Effect of microtopographical cues on human keratocyte orientation and gene expression. Curr Eye Res 36: 88-93.

Vazin T, Schaffer DV (2010) Engineering strategies to emulate the stem cell niche. Trends Biotech 28: 117-124.

Vernon RB, Gooden MD, Lara SL, Wight TN (2005) Microgrooved fibrillar collagen membranes as scaffolds for cell support and alignment. Biomaterials 26: 3131-3140.

Wang YC, Ho C-C (2004) Micropatterning of proteins and mammalian cells on biomaterials. FASEB J 18: 525527.

Wang L, Murthy SK, Barabino GA, Carrier RL (2010) Synergic effects of crypt-like topography and ECM proteins on intestinal cell behavior in collagen based membranes. Biomaterials 31: 7586-7598.

\section{Discussion with Reviewers}

Reviewer II: Have the authors tried to use finer fibres to see how small a feature could be faithfully replicated on the FLS? If so, what is the limit?

Authors: It has been shown extensively that cell behaviour can be influenced by nano-scale surface topography. However, using collagen as a scaffold puts an inherent lower limit to the scale to which controllable topographical features can be introduced. Collagen fibril diameters range from 20 to $400 \mathrm{~nm}$ and arrangement of fibrils is anisotropic. This means that material will naturally have nano-topography of this scale parallel to any alignment. However, it is possible that collagen scaffold with aligned fibrils will allow for patterning at a lesser scale than described here when pattern is introduced perpendicular to the fibrils. It is likely that patterning such surfaces at the nano-level will play a key role in producing next generation smart biomaterials with bioactive surfaces. Consequently, using templates with dimensions greater than collagen fibril diameter should lead to successful patterning of the FLS'. 